\title{
Improving Corporate Governance and Managerial Skills in Banking Organizations
}

\author{
http://dx.doi.org/10.3991/ijac.v7i4.3993 \\ F. Capriglione and N. Casalino \\ Guglielmo Marconi University, Rome, Italy
}

\begin{abstract}
At the present, the focus on management and corporate governance of banks will play an ever more crucial role given the prevailing importance of banking institutions as a source of finance for the corporate sector. Improved board structures, administrative procedures and disclosure requirements could result in better-governed banks, which are more likely to allocate investments proficiently. Therefore, a strong corporate governance can be an important pillar for banking organizations assets, because effective boards of directors complement the regulatory oversight. Efforts to promote good corporate governance in financial institutions face a number of challenges. One is getting the most innovative and experienced people to serve on bank's boards and management, given the complexity of the business environment and new financial products. This requires also finding competent leaders who also understand new business opportunities and their risks, have a healthy scepticism and take decisions quickly. Regulatory and supervisory frameworks alone cannot guarantee financial stability. Effective corporate governance, change management approaches and innovative managerial skills can act as a first line of defence for banks and financial institutions, against any impending crisis and unethical business practices.
\end{abstract}

Index Terms-Corporate governance, banks, managerial skills, distance learning, change management, corporate responsibility and culture.

\section{INTRODUCTION}

Last five years were characterized by a strong qualitative and quantitative increase of training investments in banking sector, all planning in order to achieve progressive automation of new business areas and a quick introduction of innovative services and processes. The trend analysed is represented by the increasing of Human Resources (HR) function role, with regard to enterprise strategies, like a key-factor to augment productivity and to support new value creation [1]. The growth of innovative financial services is becoming a reality and carries European banks in a stronger competition in the global financial market.

Concerning priorities that banking sector is facing, are emerging the followings: 1. compliance and risk management; 2 . corporate efficiency increasing; 3 . infrastructures revision and innovation; 4. professional skills of managers; 5. effective leadership; 6. transparency. Considering this context, banks are checking own systems, with focus on internal architectures, in order to comprehend the effective compliance with SOA (Service Oriented Architecture) paradigm that is becoming the key-factor to surpass the architectural rigidity and to augment corporate per- formance. In this contest, it is important to consider the "cost management" strategy that banks are implementing and deciding to adopt for the next years [1]. Besides, we can observe two main strategic orientations: costs cutting and M\&A processes. Therefore, we will try to interpret these strategies, in order to comprehend the future implications. Second, in terms of strategy and efficiency definition, the article will describe recent studies that debate about strategic human resources strategy, in order to comprehend main benefits and advantages. We want to represent some main strategic skills to fit better the new organizational structures, with support of new advanced managerial skills [2] and finally, we will analyse causes and reasons, which have conducted to the choice, the organizational and economic impacts, critical items and benefits. The concept of good corporate governance has been described in different ways, highlighting its various aspects. Following are some definitions that can be considered:

- corporate governance is holding the balance between economic and social goals and between individual and communal goals [3];

- according to OECD, corporate governance structure specifies the distribution of rights and responsibilities among different people in the corporation, such as the board, managers, shareholders, and the stakeholders and spell out the rules and procedures for making decisions on corporate affairs;

- corporate governance is the system by which business corporations are directed and controlled by applying principles of transparency, accountability, responsibilities, independence and fairness;

- according to World Bank, corporate governance is a set of rules, standards and organizational concept $\mathrm{s}$ in economics that regulate the behaviour of companies, directors and managers;

- corporate governance is a mechanism in which shareholders of a business entity exercise control over management and/or other parties within the company to ensure that all their interests are protected [4].

A strong corporate governance can be an important pillar for banking organizations assets, because effective boards of directors complement the regulatory oversight. Regulatory and supervisory frameworks alone cannot guarantee financial stability. Strong corporate governance, change management approaches and innovative managerial skills can act as a first line of defence against any impending crisis and unethical business practices. 
PAPER

IMPROVING CORPORATE GOVERNANCE AND MANAGERIAL SKILLS IN BANKING ORGANIZATIONS

\section{THE SPECIFITY OF BANKING GOVERNANCE}

The specificity of the regulatory regime of banking governance is founded on the fact that the financial intermediaries play a special role in the economic process, which is inevitably affected by their actions.

Since the past, economic theory has, in fact, showed that the combination of savings, investment and income pillars of a formula of productivity and growth successfully tested since the English industrial revolution - takes advantage of an intermediary action that make possible the translation of resources from the centres of formation of saving to those that use the saving, affecting the proper functioning of markets [5]. To the activity of banks is left, therefore, the possibility of achieving purposes that go beyond the business interests of the banks themselves and, often, the interests of investors and shareholders. Therefore, are clear the reasons for which the structure of such institutions, at the normative level, appears characterized in terms of peculiar connection between "management" and "control of risks"; reasons related to the purpose of the regulator to draw up an organizational scheme suitable, on the technical level, to ensure the stability of these subjects. At the base of such disciplinary orientation there is, indeed, the feeling of being in the presence of an activity that is able to reflect on the overall outlook for economic growth in the country, taking into account, among other things, the negative impact arising from situations of mala gestio (whose response is conceivable in the course of several corporate events). On this point, it seems relevant the consideration according to which the entrepreneurial paradigm, the foundation of the notion of "banking activity", requires governance structures closely linked to the prudential supervision that distinguishes clearly the subjects of banking sector. Consequently, the normative construction of governance, not being able to refer to the whole purpose of "supervision", should regard to the realization of activity carried out on the lines of "sound and prudent management" and directed to the "overall stability, efficiency and competitiveness of the financial system" [6]. As a result, it is needed to adapt the principles valid for the firms in general to the specificity of the banks, according to the regulatory criteria that induces it to not limit the scope of the assessments related to the banking governance, to the sphere of interests of the shareholders. The reference to modern market context together with the effects of the complex relations conducted within the corporate structure - allows, in fact, overcoming the view of governance linked to the position of holders of the property and, therefore, sized on exercise of corporate control. Therefore, the need to exclude interpretations of firms reality that assume a limited functionality to the maximisation of shareholder value, intended primarily as the discounted value of expected returns for the future [7]. In addition, it cannot be neglected to consider that the activities of banks, while reflecting the neutrality of the "business of firms", as was pointed out in the past by an eminent doctrine, is oriented to the achievement of public interests. Consequently, are justified the exceptions to the common rules and the compression of statutory autonomy of such entities, while remaining the peculiarity of the relationship between "activities and organization", at the base of the reality of firm. At the same time, we understand the reason why the components of this relationship, on the dynamics of the market, assume a specificity related to the organizational choices (directed to achieve the company's profitability), or the presence of administrative controls underlying the protection of public interests that characterize the financial matters. It is clear that the structure of governance of the banks begins as necessary requirement of corporate stability in the terms indicated above. Indeed, the criteria of the forms of administration and control of these institutions are necessarily related to the "organizational system", imposed by the special rules for the soundness of management and, more generally, for the achievement of the overall balance of the industry. In this sense, is oriented the provision in the European context of corporate rules directed to introduce effective measures of protection of risks, which - if not adequately monitored - can affect not only 'the objectivity and impartiality of the decisions' strategic and operative taken by banks (i.e. execution of certain transactions, allocation of financial resources, grant funding, etc.) [8], but also the smooth functioning of the financial system. It can be observed, therefore, that the system of corporate governance in the banking sector is instrumental to the proper exercise of banking activity. This structure is reflected in the determination of strategic plans and business objectives (which is linked to the choice of particular organizational forms), as well as on the management of current operations. Indeed, the proper performance of the functions assigned by the disciplinary system to the administrative and control bodies' places at the base of the ability to create value and generate income, becoming a primary factor in the realization of the core business of the banking firm. Thus, the bank management becomes the primary factor for evaluating the criterion of "sound and prudent management"; it is needed to refer it for monitoring the adoption of measures and behavioural lines suitable to ensure the stability and continuity of the firm. The accountability of corporate bodies is, in fact, guarantee of a balanced performance of the duties and powers assigned to the same subjects; it allows the banking company to fulfil the requirements placed to the safeguard of balance of public and private interests, which - as mentioned above - characterize the essence. It can be drawn a first conclusion: the knowledge of the participants that form the corporate bodies, the independency of individual members and the credit institution (such as to ensure their removal to dangerous influences, even if unconscious), the dynamics of information flows, transparency with respect to all stakeholders identify the relevant aspects of the governance of banks; therefore, it is also explained the reason why the rules of banking sector manage the contents. In support of these rules there is, in fact, the intent to preserve the observance of operational criteria that ensure the appropriateness of the decision-making processes, removing the lasseiz faire generally left to the internal structure of entities. This is in the belief - shared especially in light of the experience of recent financial crisis - that the market is not always able to use in a positive way the freedoms granted by law and supervisors.

\section{THE BODIES WITH AN ADMINISTRATION AND CONTROL FUNCTION: THE GOALS OF THEIR FUNCTION AND PROFESSIONAL SKILLS}

For guaranteeing an appropriate corporate balance, corporate governance regulation for banking institutions should avoid an excessive concentration of powers in the hand of few subjects as well as disproportions within corporate bodies, which may adversely affect readiness 
PAPER

IMPROVING CORPORATE GOVERNANCE AND MANAGERIAL SKILLS IN BANKING ORGANIZATIONS

and effectiveness of the decision making process likewise the functioning of the banking business. Accordingly, the mentioned disruptions may limit the internal governance framework of banks, especially with regard to the allocation of powers within governing bodies. Thus, an effective interaction among strategic supervision and management procedures and, therefore, the centralisation of such functions should be ensured. In addition, the supervisory board should efficiently act as a referee for banking authorities. As a result, in a context where the identification of each corporate function is crucial to ensure 'sound and prudent management' as well as the overall financial stability, executives play a central role in defining corporate governance arrangements. According to this view, a valuable corporate interaction is a prerequisite for a reliable earning capacity of financial institutions. In this line of thought, the decision making process should not be compromised by misleading information or distorted technical evaluations which directors would adopt in order to comply with top management's needs. Hence, ensuring the relationship within board's members requires detailed rules, particularly with regard to delegation of powers, establishment of general manager's powers by the statute - who manages and leads internal control systems - and in defining the role of the chair of the board. The latter, by promoting internal debate, balancing powers in accordance with board's tasks and spreading information, performs a crucial role in achieving the objectives described above. Within the outlined framework, the corporate governance model for banks is heightened by independent nonexecutive directors, which should guarantee shareholder's powers through the avoidance of conflicts and any form of centralisation of prerogatives.

This represents a significant step forward with the purpose of enhancing transparency and operational fairness as it should improve responsibility and prevent overlap of interests being beneficial for the corporate management as a whole. Conversely, the board of directors should adequately perform with respect to the management of the banking business, which is a reserved activity. In fact, in order to secure the prudential soundness of banks a wide range of professional skills is required. Nevertheless, these abilities could offer the expected contribution only if the board adopt actions in accordance to a cohesive view of corporate targets (in other words, within a corporate environment that respects technical and decisional prerogatives based upon a decision making process free of constraints). In this respect, the role of supervisors (e.g. board of statutory auditors, supervisory board, and management board) should be examined. Indeed, it should be emphasised that they monitor the compliance with the statute and corporate law as well as the application of the banking regulation. Consequently, they play an essential role for the implementation of the ordinary and special financial regulation as well as verifying the corporate structure of financial intermediary. In addition to the compliance with the banking regulation, supervisors are in charge of the supervision of internal control systems (which comprehends the 'sound and prudent management' of the bank, "with specific regard to the control of risks and accounting regulation"). Finally, it should be reminded that corporate governance for banking institutions was recently reformed with the implementation of the Directive n. 2013/36/EU ("CRD IV"). Indeed, in order to ensure the execution of functions the board, a diversified composition of the same in terms of professionalism and gender was introduced. Therefore, it is observable a trend which tends to achieve high levels of corporate efficiency by adopting a more coherent board composition and formative plans for key personnel. The mentioned regulatory intervention - by taking into account systemic considerations, which have been just evaluated until recently - aimed to link professionalism of executives with the incoming Single Supervisory Mechanism.

Accordingly, the directive clearly attempts to sustain the internationalisation of financial institutions, which implies an alteration of their business models. As a result, in order to afford the changes of the global financial system as with those we are experiencing nowadays, a banks' corporate governance is required to be based upon professional skills with the purpose of preventing and managing criticalities, which may adversely influence balance sheets. Therefore, bank officers' aptitude should be considered in order to conduct a leadership role, to communicate and interact with the management, to oversee transformation and to comply with 'business ethic principles'.

\section{LEADERSHIP ROLE, BUSINESS COMMUNICATION ADOPTION AND CHANGE MANAGEMENT}

In view of the above, it is quite plain to acknowledge that the possibility for the banking firms to hire qualified management (having the professional skills required for the specific activity to be pursued) firstly depends upon the level of education. In this regard, it's important to consider the degree of executive education of the bank's managers who should have a wide range of professional competences, consisting not only of the notional background acquired at the university but also of a knowledge apparatus gained by attending content-specific programs. Such courses must provide the proper tools for integrating technical capabilities (that are held by people attending Schools of Management) with the data diffused among the general audience by high-performing functional experts. In fact, it is believed that the cultural enrichment that informally (or at least indirectly) is achieved with these programs immediately puts the potential managers in contact with the corporate entity that they will be asked to run on daily basis. It becomes essential to know in advance which issues will underlie the decision-making choices as well as which difficulties (to be overcome) will be faced. In addition, this is crucial in order to identify the management criteria designed to formulate technical evaluations along with behavioural indications.

The role of leadership presupposes not only a full judging capacity in evaluating the economic convenience of the different choices that the members of the Administrative Board are called to undertake, but also the possibility of adopting a holistic approach that would help the bank's operator in elaborating appropriate and context-tailored decisions while exercising his own functions. In particular, it should be borne in mind that, within the banking sector, the managers' action must be addressed by a prudential logic that is configured as the guiding principle for their conducts and, therefore, as the essential assumption for the management of profitable credit institutions. To follow such a logic requires a critical attitude to analysis, which is expression of a complete technical knowledge of the subject at issue and, at the same time, the ability to perform evaluations that use historical series and past successful evidences as parameters for the adoption of 
PAPER

IMPROVING CORPORATE GOVERNANCE AND MANAGERIAL SKILLS IN BANKING ORGANIZATIONS

future solutions. In other words, in order to legitimately acquire leadership roles, it is deemed necessary the presence of an educational attainment, enabling future managers to promptly discover the typical risks characterizing the operational practices; and taking into account that the decision-making capability of the Board is a primary factor for determining the prospects for corporate earnings.

Additionally, it is closely connected with the identification of the criteria at the basis of top management positions the ability of managers to give harmony to the relationships within the Administrative Board (i.e. the ones existing between the chair and directors) and to the relational linkages that it has with the Managerial Board. As it is possible to infer from the information given by the European special regulation, it stands a strict nexus between management efficiency and decisional appropriateness: the latter implies that the proper functioning of the strategic and operative bodies derives from the respect for assigned roles as well as from the absence of prevarications. This implies transparency in the relationships, and thus continuous disclosure as it is requested by the top management; additionally, the data and the communications notified by the executives are supposed to be detailed (and truthful) and able to unequivocally represent the elements being evaluated. Hence, one must attribute centrality to the internal communication, whose effectiveness constitutes the basic assumption of the firm-level relationships. An adequate internal system of interaction permits to convey not only the information underlying the decisions to be made, but also multiple messages, such as the sharing of corporate values and ethics codes as well as the management of cultural, generational and gender differences. Therefore, in the logic of corporate profitability, it is necessary to improve the forms of communication: the management is asked to play its role independently of hegemonic pressures, which may prevent executives from discharging their duty of disclosure (and providing the company with adequate and reliable reports). Conversely, with the aim of pursuing a cultural improvement within the organization, it is important to diffuse an effective, motivating and engaging communication that (when key issues occur and are addressed by the bank) is capable of coaching the human resources and providing them with the minimum required skills for fulfilling their tasks. From a different perspective, the change management embodies a significant aspect of the banking activity peculiarities and of the evolutionary process of globalization that we are living nowadays. Indeed, in a competitive environment are more prone to survive and be rewarded by the market those who know first intercept the directions of change and succeed to immediately identify the changes to be implemented within their organization. It is well known as the intense process of globalization that has affected the planet in the recent decades, has imposed financial activity to cross the national borders, by putting into contact many business realities. This produced several effects that influence, among other things, the corporate governance arrangements of companies (especially banks). In this scenario, the administration and control bodies of the banks should be able to promptly acknowledge (and prevent) the changes in production processes induced by the evolution of the operational and institutional context. In facing the "roots of the change", banking managers are required to interpret their roles in innovative ways, by adopting appropriate transformations of the internal organizational framework, as well as new modes of interacting with the other financial intermediaries. Hence, the importance attributed to the cultural level of the persons having the role of connecting through appropriate structural modifications, the business reality to the ongoing systemic innovations; in particular, it should be taken into consideration the ability of organizational diagnosis and analysis of the dimensions of the complexity that the occurred change has generated.

The assessment capability of managers is crucial for the adoption of measures suited to make the improvement possible and - with regard to the implications of globalization - to support forms of development free from the former institutional localism, which was a typical feature of the "closed" economic systems (i.e. not moving towards a standardization of rules and practices).

\section{BUSINESS ETHICS PRINCIPLES}

In qualifying the behaviours of banking managers, it is particularly significant the search for a viable application of ethics in the business world, followed by the introduction of deontological rules aimed to the protection of social needs. The correlation between rules, provided services and operational correctness connects finance to social issues and combines the technicality of the banking activity with the principles of ethics. This obviously generates positive effects on the foundations of the legaleconomic theory oriented to the study of the firm, of the market organization and of the financial relationships among it. In light of the above considerations, a methodological approach to analyse economic reality and redefine the purpose of financial activity is now emerging. Indeed, according to the centrality of human beings within the evolutionary process (which allowed the economic development), the reconciliation of rationality (which may be abused) with binding ethical rules is becoming crucial [9]. It is also clear that such interpretation of financial interactions permits us to reconsider the connection between economics and individuals. To accomplish that purpose, the implementation of ordering criteria able to reform financial actors' behaviours and, consequently, to profoundly change financial activity is widely. In fact, providing day-to-day attention to others' needs - ethical interdependence among humans, which implies the defection of individualism and inequalities - is required.

Consequently, the establishment of 'unhealthy alliances' between market practices and information technology, which may neglect human dignity through the implementation of speculative patterns, should be suspiciously examined. To assume a cultural level and a professional education of banking executives based on the principles of business ethics implies, therefore, seeking for a project of economic and financial operability in which intermediaries care about others' positions and interests. Moreover indeed, adopting ethical conducts in the management of the bank, means to orient activities not only to the generation of profits (widely considered the main goal of the market), but also the observance of principles (in primis: equality and solidarity), representing the guidelines of a new scheme of agere that sanctions those operational practices that neglect the human dignity. We identified the requirements of a profound change in the practices diffused among the sector's members. Embracing ethics in the business field by respecting others' positions and interests should ensure the necessary protection of others' 
PAPER

IMPROVING CORPORATE GOVERNANCE AND MANAGERIAL SKILLS IN BANKING ORGANIZATIONS

savings and avoid running unjustified risks; it should lower the cases of a laissez faire where speculations, competition distortions and abuses take place. Accordingly, the concern recently pronounced by Pope Francis is particularly relevant; in fact, he reminded people that "money" has become an "idol" according to "ideologies ... (that) ... promote an absolute market freedom and ... financial speculation", and he remarked on the "invisible, and sometimes virtual, tyranny" of market's rules. The interpretation of financial interactions from an ethical point of view is a precondition for a proper understanding of the market economy. Within the latter, in order to promote an equal sharing of economic benefits for all those who (albeit in different manners) are involved in the financial processes, the respect of counterparties - intended as the contemplation of dignity, equality and solidarity within humans - should be a prerequisite of human action.

According to this perspective, by adopting the function of ethics as the main criterion for the realization of social objectives, it could be considered as a constitutive market element [10]. Notwithstanding this, the 'special status' which characterises the regulation of the financial sector cannot be neglected. In fact, legal theories concerning companies, market organisation and internal market relationships are still holding weight. Admittedly, permitting exemptions to compliance with certain rules (such as, for example, the assessment of creditworthiness and prudential management) appears to be unfair in order to protect investor confidence, which certainly represents a considerable social value. Thus, to reconcile market protection and solidarity seems to be achievable.

Consequently, it has been widely claimed that, in order to guarantee a high standard of welfare and economic development, the functioning of financial institutions should be based on the concept of healthy finance [11].

\section{PRIORITIES FOR THE BANKING SECTOR}

In many cases banks are conservative and technocratic organizations that are often latecomers to innovative institutional governance. Furthermore, structures designed for corporate governance purposes are often far from optimal for the purposes of these kind of organizations. Too often internal culture is overly rigid [12], or preoccupied with legacy management issues that crowd out strategic management and institutional governance reform. Banks are now under increasing pressure to demonstrate better institutional governance.

They need to "adapt not adopt" - customising good governance practices to their unique needs. The sector has witnessed an unprecedented restructuring and consolidation trend in the financial services industry across the globe. In the last fifteen years, mergers have led to a consolidation of banks and the emergence of regional powerhouses. In Europe, mergers have been prominent as well. Cross-border mergers are relatively frequent and on a domestic scale, mergers typically involve large universal banks and are often spectacular.

The coincidence of the consolidation trend in the financial sector with increased competition have led to believe that the massive banks reorganizations are a response to a more competitive environment. Banks need to examine all possible ways to eliminate inefficiencies from their cost structures, for example, by merging with other banks and realizing scale efficiencies through elimination of redun- dant branches, back-office consolidation and outsourcing strategies, or by persevering with a strong cost cutting policy [13]. It is important to observe that several factors, overall managerial and regulatory frictions, affect the potential realization of scope and scale economies, linked to a focused training strategy. For example, a merger between two financial institutions may not readily lead to scale and scope economies because the integration of the cultural aspects may take time and more investments in training activities [14]. At the end, implementation issues are crucial because it is a "core activity" of banking market. There are enormous differences between the "best practices" and "average practices" inside the financial institutions. Cultural differences between merged entities play an important role.

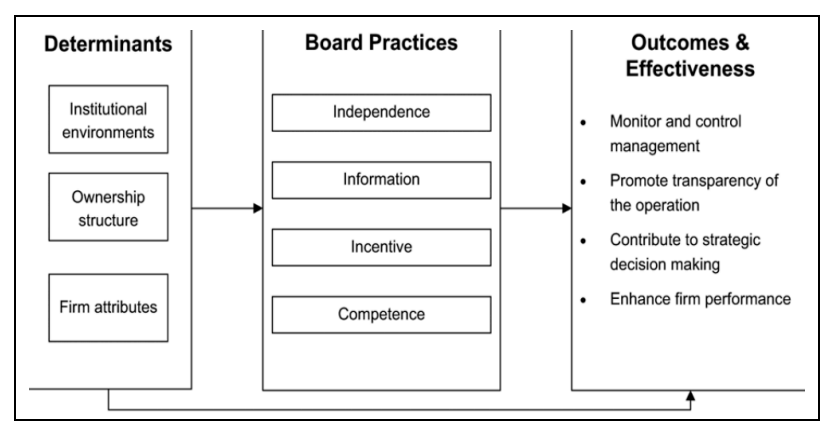

Figure 1. Board practices and effective outcomes

Some empirical studies say that cost synergies in last European mergers are represented by $30 \%$ of cases. In this sense, the chance of a focused managerial learning approach is most likely of great importance.

\section{ROLE OF PROCEDURES AND TRANSPARENCY}

Banks lend money that are, in effect, borrowed from depositors. Depositors are, thus, stakeholders specific for the banking sector. Boards of directors and managers need to take into account and protect the interests of depositors. This is a distinct challenge of corporate governance and requires a special attention in order to maintain the stability and confidence of depositors in the banking system. Controlling shareholders, often appoint all directors, which can undermine the independence and objectivity of the board. Director independence is an important issue as well in countering political interference and in effectively monitoring management. Independent directors can play a critical role in preventing abusive related party transactions (including lending), which may have more serious consequences in banking than in most other industries [15]. Well-defined independence criteria and mechanisms for ensuring compliance are fundamental. Banks' boards of directors should ensure the implementation of existing managerial practices regarding lending exposure to customers, including related borrowers. Independent directors should also play a critical role in this respect. Board members should act in accordance with their duties of care and loyalty. These duties are perceived to be more important in the case of banks, as they manage public money in the form of deposits. Personal integrity and competence should be key criteria for appointing bank directors, in order to ensure that bank boards function effectively.

Boards of directors should approve and oversee the development and implementation of the strategic objectives of the bank. "Fit and proper" tests are particularly im- 
portant for the banking sector, both upon the position of directors, but also on a permanent source.

Banking supervisors are expected to place more emphasis on securing sound corporate governance of banks they supervise rather than to focus only on regulatory compliance. Specialised board committees play an important role in supporting decision making in boards of banks as well [16]. The establishment of a risk management committee, in particular, should be encouraged, in order to oversee the bank's risk management system and ensure that the risk policy of the bank is properly implemented. Internal and external auditors, as well as other officers exercising compliance and legal functions play an important role in overseeing banks' risk management and control systems. They need to ensure that the banks' financial statements represent the financial position and performance of the bank fairly in all material respects. Boards of directors and senior management rely on the work of the internal and external auditors, and of others, performing control functions as an independent check on the information received from management. In particular, internal and external audit functions, underpin the long-term soundness of operations and performance of banks [17]. Transparency is essential in enabling shareholders, stakeholders and market subjects to effectively monitor and hold accountable the board of directors and senior managers.

For instance, we considered the clear PASA relationship model guided by the principal insisting that subagents abide by the corporate governance metrics of the principal, over and above simple legal and regulatory constraints [18]. An example is fund managers setting up "ethical funds" where firms are only invested in, if they can demonstrate commitment to the relevant ethical framework. This commitment can be demonstrated throughout the firm rather than simply in its public statements. As part of this same dynamic, regulators are now asking for data on managers' professional competencies further down the management chain than just the board. Good transparency and disclosure are relevant to banks as well as this is the only way to facilitate market scrutiny, and enhance the ability of supervisors and stakeholders to effectively monitor them.

Both listed and closely held bank need to apply high standards of disclosure. This concerns private banks with a sole owner, because they participate in payment systems and accept retail deposits and thus, their soundness affects financial stability. Disclosure is of particular importance especially to banks with complex interlocking ownership structures. International accounting standards and practices and the guidance of the Basel Committee need to be reflected by national laws and managerial practices in banking organizations.

No-listed banks, as far as they are required to disclose their information to the public, should also adhere to these standards and practices [19]. Therefore, there is a need for cooperation between banking supervisors, securities regulators and stock exchanges on listed banks disclosing.

\section{TRAINING SKILLED MANAGERS FOR UNDERSTANDING RISKS AND TAKING DECISIONS QUICKLY}

Efforts to promote good corporate governance in financial institutions face a number of challenges. One is getting the right people to serve on boards and management, given the complexity of the business environment and

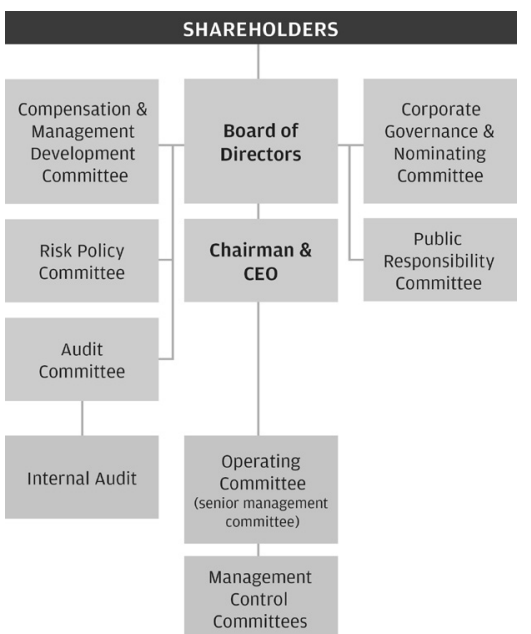

Figure 2. An example of a committee structure that enhances the board's oversight of the bank's management

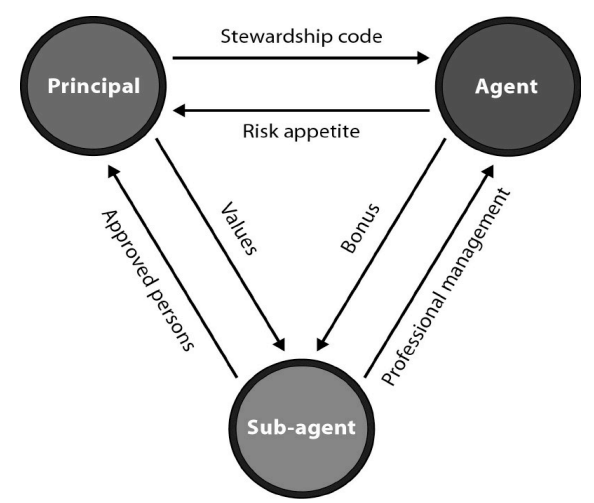

Figure 3. The Principal Agent Sub-Agent Model (PASA)

new financial products. This requires finding competent leaders who also understand the business products and risks, have a healthy scepticism and know how to take decisions quickly [20]. Taking into account what we have learned from previous years, a focused and holistic approach to promoting good corporate governance could have the following components:

- effective leadership (e.g., through requirements on financial institutions to have audit, risk management, nomination and remuneration committees);

- promoting corporate values, culture and ethical values (embedded in various risk management and prudential guidelines);

- shareholder activism (increased role of minority shareholder watchdog groups);

- regulation and supervision (through revised guidelines on connected lending, internal audit functions and fit and proper persons);

- consumer activism (e.g., by educating consumers, providing advisory services to consumers and greater emphasis on corporate social responsibility;

- enhancing transparency (e.g., through the requirement for the statement of internal controls and in the annual reports of financial institutions and proper accounts and financial reporting);

- effective use of auditors (e.g., through greater emphasis on auditor independence and expectation of regulators on auditors). 
Banking supervisors should also help banks introduce training programmes, which would increase the awareness of boards' responsibilities in terms of corporate governance [21]. Directors' skills should be enhanced by ongoing training programmes that underscore the professional, ethical and technical demands imposed by the increasingly complex industry practices. It is estimated that only $35 \%$ of banks conduct formal training for board members, as reported by UAB.

This may be in part related to the fact that board members believe themselves to be "above training", and in part due to the fact that internal corporate governance knowhow is lacking, as are qualified external trainers. In the wake of the crisis, some countries have considered introducing measures whereby annual training for board members will become compulsory [22]. Such training could be provided by, for example, stock exchanges or professional associations such as banking industry associations or institutes of directors. Continuous monitoring of board competencies is necessary to ensure that appropriate skills are represented on bank boards and that they continue to function effectively. Board evaluations, which incorporate an assessment of member competencies, are mandatory for banks in some European countries, but are optional in most other jurisdictions. As a result, only $20 \%$ of banks are estimated to conduct board evaluations, as reported by IFC-Hawkamah.

Therefore, it is recommended that the performance of individual board members and the board as a whole should be regularly evaluated.

\section{THE EXPERIENCE OF MASTER IN REGULATION OF THE ACTIVITIES AND THE FINANCIAL MARKETS}

The Master provides a comprehensive set of materials and learning tools aimed at enhancing the role that directors can play effectively in their boards [23]. It also provides approaches that they can use to ensure that boards and managers follow the best practices [24]. The emphasis throughout the training is on developing leadership and analytical skills. The Master has a unique emphasis on training that maximizes the learning experience. Each module is designed to stimulate discussion and debate and uses interactive strategies to enrich training for adult learners. By encouraging managers to draw on personal experiences, their development is reinforced by sharing knowledge and boardroom practices in a way that addresses the challenges that many directors face [25]. The modules comprise user and training guides, five curriculum modules, a case study that traces the evolution of a hypothetical bank as it considers corporate governance reforms, and the website with all online contents (http://mercatifinanziari.postlauream.luiss.it/materiali/).

The Master training activities, correspond to 60 ECTS (European Credit Transfer System) credits and represent in particular 1,500 total hours of learning, of which 300 hours are dedicated to classroom lessons, 30 hours for participation in conferences and seminars, 70 hours of laboratory and simulations, 650 hours devoted to personal study, 450 hours for the Master's thesis preparation.

In particular, the programme includes the following focused subjects:

- Alternative means of resolution and reconciliation;

- Bank assurance;

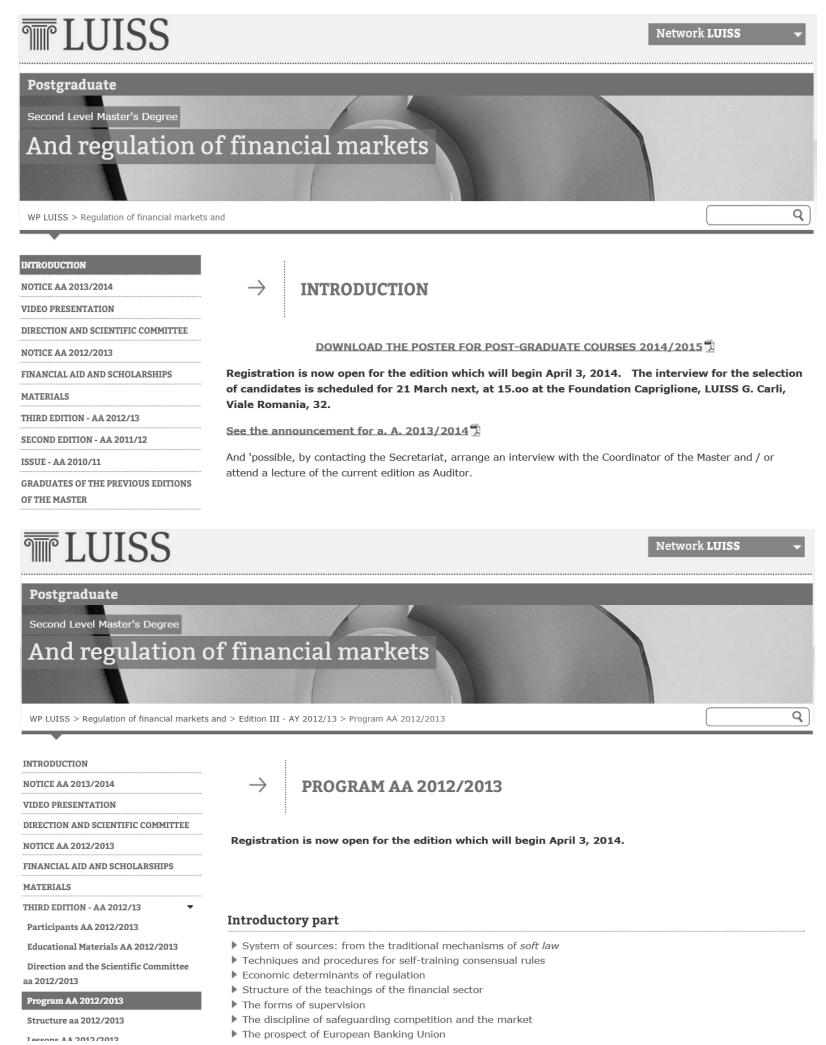

Figure 4. Some screenshots of the online platform

- Banking and financial intermediaries;

- Banking and types of contracts;

- Banking information systems;

- Business communication;

- Business ethics;

- Business organization;

- Business strategy;

- Change management;

- Conflicts of interest;

- Consortia and guarantee consortia;

- Consulting and management of individual portfolios;

- Corporate governance and corporate control;

- Corporate responsibility and culture;

- Decision making processes;

- Dematerialization of documental' flows;

- Disputes relating to banking and financial;

- Economic determinants of regulation;

- Exceed the crisis for banks and other intermediaries;

- Financial advisors and outsourcing of financial instruments;

- Financial conglomerates;

- Financial crimes and prevention;

- Financial Statements and accounting rules;

- Forms of supervision;

- Human resource management;

- Independent auditors;

- Innovative payment systems;

- Investment firms;

- Knowledge management; 
- Leadership techniques and approaches;

- Leasing, factoring, forfaiting and other contracts for businesses;

- Organizational change;

- Organizational design;

- Penalty proceedings;

- Principles for enhancing corporate governance;

- Privacy protection in banking, finance and insurance;

- Rating agencies;

- Regulation of real estate finance;

- Securitization techniques;

- Solicitation rules and tender offer;

- Sovereign wealth funds;

- Strategic human resource management;

- Structure of the teachings of the financial sector;

- Structured finance and derivatives transactions;

- Supplementary supervision;

- Techniques and procedures for self-training consensual rules;

- The collective asset management;

- The discipline of anti-money laundering and countering wear;

- The discipline of safeguarding competition and the market;

- The financial activity: objects (products, financial instruments, securities, etc.);

- The insurance business;

- The insurance contracts;

- The learning organization;

- The markets and regulated markets;

- The prospect of European Banking Union;

- The protection of consumers of financial services;

- The relationship bank - customer and the systems of centralization of risks;

- Traditional mechanisms of soft law;

- Transparency rules and methods.

\section{FACTORS FOR AN EFFECTIVE TRAINING ACTIVITIES DEVELOPMENT}

It is required surely to fully improve the ability and quality of executive managers and make them problem solver, decision maker, uncorrupted, self-disciplined and professional at every level [26]. To obtain these skills, often they should participate to training activities as corporate academies, executive leadership schools or other training organizations approved by the human resource offices [27]. An analysis of the main drivers to introduce better performance and a real change in the banking sector was undertaken. We looked at the economic, social, legal and environmental contexts of banking and financial sectors to develop and implement an accurate training strategy [28]. The following factors were identified to better develop effective training activities:

\section{Economic factors:}

- resource constraints owing to new European and global macroeconomic situation;

- drop of profits at national and European levels.
- Legal and environmental factors:

- traditions of a law based approach respect to a significant managerial attitude;

- transferability of several banking best practices and approaches to other real situations;

- primacy of the banking regulation to determine managers competences and careers;

- lack in many banking organizations of dedicated offices and training best practices.

\section{Organizational and social factors:}

- motivation of managers for self-development;

- change management;

- coaching people;

- cross-cultural and diversity management;

- ethics approaches and impacts;

- opportunities for many managers to meet international best practices in the European financial context;

- implementing a real change management reducing any organizational resistance;

- lack of an innovative management culture in traditional or older banks;

- knowledge and individual experiences exchange between executives and managers;

- training currently has low status and acceptability for these kinds of people. Sometime it is viewed by participants also as additional to day-to-day work.

For the Master has been implemented a pilot to demonstrate the effectiveness of the overall system (applications, contents and organizational aspects) and to promote the use of distance learning in the banking field.

After one year, the project concluded its pilot phase and the results were analysed. With a view to stimulating cooperation and the exchange of best practices in Europe, its purpose is to build and test an innovative model of transnational networking, thanks to the active involvement of other banking schools and institutes, and to their participation in a scientific committee of experts, established to define common guidelines [29]. A training course held the last year with a class composed of 20 participants from several banking and financial organizations. The class was composed mainly by senior managers and executives. The training programme has been defined to reach the following learning outcomes:

- shared knowledge, key skills and competences to improve decisions making and better collaborate with colleagues and employees at European level;

- specific knowledge and innovative practices;

- exchange experiences and relationship practices.

Training was delivered by high-level lecturers, experts from several financial institutions and senior managers. A Master certificate was released to the participants at the end. According to these assumptions and trying to answer to some main research questions, with a study that intends to evidence the main problems related organizational aspects [30]. The application also of distance learning in managerial training encountered also some difficulties (time, motivational and continuity issues). It was adopted a basic online platform and a blended learning method. Both online and traditional classroom teaching have their 
respective advantages and disadvantages, and appropriate teaching mode is dependent on different training courses and training objects. The managerial training covers both basic theoretical contents and case studies, and is suitable for a blended learning.

\section{TRAINING METHODOLOGY ADOPTED}

The choice to adopt a blended approach, based on inclass training and distance learning, gave extremely positive and efficient results and was highly rated by managers, who were invited to assess the quality of the training through ex ante, in itinere and ex post evaluation forms. The results of these evaluations provided a very useful basis to improve and implement other Master modules in the future. According to the previous processes, the system consists of four subsystems: courses, teaching management, tutoring and platform management [31]. To fulfil these objectives, we tried to design and implement a training model of teaching, transferable and repeatable in different banking organizations, in order to enable managers to acquire the shared knowledge and a necessary country-specific background. The mixed backgrounds and nationalities of the audience and of the lecturers is an important asset.

The e-learning contents included mainly text material. Before the beginning of the course, the tutor sent to each participant an e-mail containing the access ID and password as well as all the necessary instructions for accessing the platform. The tutor followed progress made by each participant and maintained direct and regular contacts with them by e-mail. A pre-assessment quiz, an intermediate questionnaire and a final test were prepared in order to assess participants' knowledge before, during and after the learning activities. Regular contacts between the tutor and the users were kept in order to exchange information related to the overall implementation of the Master, to the individual access to the platform by each participant and to the tuning of the learning contents.

Moreover, a forum was created for each module in order to enable managers to interact with the tutor and the teaching staff on specific contents. As far as the functionality of the platform is concerned, interaction modalities proved to be quite efficient and immediate and the quick and simple description of the resources provided through a video tutorial was quite useful. From the evaluation questionnaires, it emerged that the learning contents, were rated, as a whole, as efficient, exhaustive, relevant and well-tuned with the in-class contents [32].

Following the blended learning approach, the in-class part of the Master aimed at providing a more in-depth insight of the topics tackled in the online part. A third level included country specific parts. For these sessions, participants were divided into 6 groups. In-class training was organised into 3-hours teaching days. Participants were asked to fill-in evaluation questionnaires at the end of each month and at the end of the Master in order to receive an exhaustive feedback on the overall organisation and the knowledge acquired [33]. The evaluation was made after the e-learning modules, during and after the inclass modules. Participants were asked to indicate how far they agree or disagree with the following statements:

- if they learned new ideas or skills (or both) by attending the blended modules;
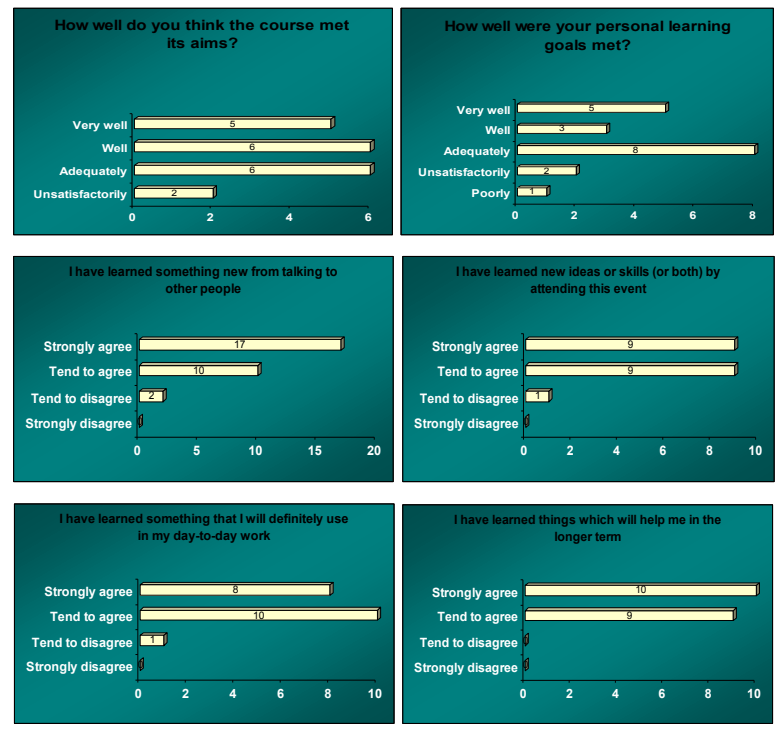

Figure 5. Some screenshot of the questionnaires' results

- if they learned something that they can definitely use on the job;

- if they learned something new from talking to other colleagues;

- if they learned things useful in the long term.

Managers were asked also to rate the training modules in their features:

- relevance of the topic covered;

- in-depth analysis of the topic;

- effectiveness of the presentations;

- efficiency and relevance of didactical tools;

- balance between theory and practice;

- involvement in the didactical activity;

- training materials/hand-outs used;

- strong interaction with other Master participants.

After the pre-assessment phase, the learning results has been very enthusiastic and the rate of the attendants was very high:

- pre-assessment quiz average: $62,23 \%$;

- on-line learning modules attendance: $73,66 \%$;

- final test average: 92,46\%;

- forum usage average: $31,23 \%$

- managers' online interaction: $18,26 \%$

The main aspects emerging from evaluation forms were the positive rating of the topics and the benefits of the modules. The final questionnaire aimed at evaluating the overall satisfaction, the attainment of the Master objectives and of personal learning goals. As a whole, participants gave a general positive feedback. Other questions more strictly related to the Master organisation and the services provided (course management, venue, and accommodation), were also included. Participants rated these aspects positively.

\section{CONCLUSIONS}

As shown by the overall active participation during the implementation of the Master, the evaluation procedure 
proved to be valid and it would be advisable to adopt the same methods for future. Possible improvements in this respect may include for instance a more complete information on the modules and selection procedures (indicating clearly the selection criteria) through the website. It was possible to identify some suggestions for improving the learning methods such as:

- the e-learning contents could be completed with other material based on different media (links to relevant websites presenting statistics or economic data of interest, slides or data to be examined during the inclass sessions, videos presenting in-depth analysis or practical cases) available in streaming or download mode. The resources needed in this respect are quite reasonable for very good results in terms of quality, processing and connection times;

- a better way to contact the tutor for a more immediate interaction (in the current version, the tutor can be contacted only by e-mail);

- introduction of more immediate communication tools in order to establish a direct line between tutor, participants, staff and lecturers (chat, wiki, etc.) and obtain a major involvement (full immersion);

- introduction of a scheduling function or "to do list" in order to provide information related to training activities or deepening;

- improvement of the monitoring and reporting features (progress report) in order to provide participants with a detailed list of topics/lessons and the scores obtained in tests and exercises;

- exclusion of the automatic transfer of messages from the forum to the whole list of platform users (to avoid the so called spam effect);

- daily in-class training could be re-organised laying greater stress on morning activities in order to leave more time in the afternoon for study and social activities.

Managers appreciated the practical approach adopted as well as the use of case studies, exercises, role-playing and team working activities. We tried to find a correct mix of financial objectives, human resources aspects [34], information systems and organizational aspects to find an accepted methodology for the modules.

It is generally accepted that, in order to compete in today's complex and rapidly changing world, executives and managers will need continuously to access to updated learning resources throughout their entire working lives.

Increased competition and financial limitations make a pressure for flexible learning to become an essential ingredient of training policies [35]. Therefore, the goal is to develop shared knowledge, to update expertise, to improve innovative managerial skills and competences.

Flexible learning methods, usually, can give more possibilities to improve managers' skills to solve problems, analyse quickly business information, and take effective decisions in banking organizations.

\section{REFERENCES}

[1] E. Miteva, "Policy Brief on Corporate Governance of Banks", OECD, 2008.

[2] J. McKee, "Corporate Governance in Banking Organizations", New Zealand PECC, 2010.
[3] A. Cadbury, "Financial Aspects of Corporate Governance", Report of Committee on the Financial Aspects of Corporate Governance, 1999.

[4] K. John, L. Senbet, "Corporate Governance and Board Effectiveness", New York University, 1983.

[5] A. Bernanke, Macroeconomics, 2005, 130 ss.; S. Labini, Torniamo ai classici, Rome, 2005, 35 ss.; D. Ehnts, A Simple Model of a Currency Union with Endogenous Money and SavingInvestment Imbalances, in Berlin School of Economics and Law Working Paper No. 16, 2012.

[6] Article 5, par. 1 of the Consolidated Italian Banking Law (Legislative Decree No 385 of 1993) and F. Capriglione, Commento sub art. 5 tub, in AA.VV., Commentario al testo unico delle leggi in materia bancaria e creditizia, Padua, 2012.

[7] M. Aoki, Corporations in evolving diversity. Cognition, governance, and institutions, New York, 2010.

[8] Second consultation of the Bank of Italy focused on "Attività di rischio e conflitti di interesse delle banche e dei gruppi bancari nei confronti di soggetti collegati", 2010.

[9] A. Sen, Collective Choice and Social Values, San Francisco, 1970 and K. Arrow, Scelte sociali e valori individuali, Etas, Milan, 1977.

[10] F. Capriglione, "Il rapporto tra etica e mercato alla luce dell'insegnamento di Papa Giovanni Paolo II" and AA.VV., "Giovanni Paolo II e le vie della giustizia”, Loiodice, Rome, 2003.

[11] E. Malinvaud, "Che cosa deve intendersi per finanza giusta? Chiarimenti preliminari ad un consenso sull'etica finanziaria", conference proceedings, 22nd of March, Bank of Italy, 2002.

[12] N. Casalino, A. D'Atri, A.M. Braccini, "A management training system on ISO standards for organisational change in SMEs", International Journal of Productivity and Quality Management (IJPQM), Inderscience Publishers, USA, vol.9 is. 1, 2012.

[13] M.A. Winner, Integrated Service Modelling for Online One-stop Government, vol. 12, 3, pp.149-156, 2002.

[14] A. Carneiro, "How does knowledge management influence innovation and competitiveness?", Journal of Knowledge Management, vol. 4, no. 2, pp.87-98, 2000. http://dx.doi.org/10.1108/ 13673270010372242

[15] S.M. Kaplan, "Discontinuous innovation and the growth paradox", Strategy and Leadership, March-April, pp. 16-21, 1999. http://dx.doi.org/10.1108/eb054631

[16] P. Birkinshaw, "Freedom of information", Parliamentary Affairs, 50, 1, pp.164-181, 1997. http://dx.doi.org/10.1093/oxfordjournals. pa.a028711

[17] N. Casalino, “An Innovative Model of Transnational Learning Environment for European Senior Civil Servants - Organizational Aspects and Governance", Proceedings of ICEIS, INSTICC, pp.148-153, 2009.

[18] A. Tucker, "Governance and Reputation Risk", QFinance, Bloomsbury Information, Qatar Financial Centre Authority,2011.

[19] M. Khosrow-Pour, N. Herman, "Critical issues of Web-enabled technologies in modern organizations", The Electronic Library, vol. 19, no. 4, pp.208-220, 2001. http://dx.doi.org/10.1108/ EUM0000000005745

[20] G. Lee, Y.H. Kwak, An Open Government Implementation Model, Using Technology Series, Washington, 2011.

[21] H. Chesbrough, "The New Business Logic of Open Innovation", in Strategy \& Innovation, 1, pp.11-15, 2003.

[22] S. Dawes, "Stewardship and usefulness: Policy principles for information-based transparency", in Government Information Quarterly, 27, 4, pp.377-383, 2010. http://dx.doi.org/10.1016/ j.giq.2010.07.001

[23] R. Agrifoglio, C. Metallo, L. Varriale, M. Ferrara, N. Casalino, M. De Marco, "Assessing Individual Learning and Group Knowledge in a Wiki Environment: An Empirical Analysis", in Klement E.P., Borutzky W., Fahringer T., Hamza M.H., Uskov V., Proceedings of Web-based Education - WBE 2013 conference, IASTEDACTA Press Zurich, Innsbruck, Austria, 2013.

[24] H. Darbishire, Proactive Transparency: The future of the right to information? A review of standards, challenges, and opportunities, Washington, MA, WBI, pp.1-60, 2009. 
[25] Z. Jin, "Organizational innovation and virtual institutes", in Journal of Knowledge Management, vol. 3, no. 1, pp. 75-83, 1999. http://dx.doi.org/10.1108/13673279910259420

[26] F. Fontana, G. Lorenzoni, "Knowledge Management", Luiss University Press, Rome, 2004.

[27] E.H. Kessler, A.K. Chakrabarti, "Methods for improving the quality of new product innovations", Proceedings of the Portland International Conference on Management and Technology, PICMET, pp.405-408, 1997.

[28] P. Miller, "Interoperability: What is it and why should I want it?" Ariadne Magazine, 2000.

[29] N. Casalino, F. Buonocore, C. Rossignoli, F. Ricciardi, "Transparency, Openness and Knowledge Sharing for Rebuilding and Strengthening Government Institutions", in Klement E.P., Borutzky W., Fahringer T., Hamza M.H., Uskov V., Proceedings of Web-based Education - WBE 2013 conference, IASTED-ACTA Press Zurich, Innsbruck, Austria, 2013.

[30] S.A. Chun, S. Shulman, R. Sandoval, E. Hovy, "Government 2.0: Making connections between citizens, data and government", Information Polity, 15, pp.1-9, 2010.

[31] F. Fontana, M. Caroli, "Economia e gestione delle imprese", McGraw-Hill, Milan, 2003.

[32] H.A. Simon, "Applying Information Technology to Organization Design”, Public Administration Review, 33(3), pp.268-278, 1973. http://dx.doi.org/10.2307/974804

[33] D. Soares, L. Amaral, "Information Systems Interoperability in Public Administration: Identifying the Major Acting Forces through a Delphi Study", in Journal of Theoretical and Applied Electronic Commerce Research, vol. 6, issue 1, pp. 61-94, 2011.

[34] S. Dawes, "Interagency Information Sharing: Expected Benefits, Manageable Risks", in Journal of Policy Analysis and Management, vol. 15, no. 3, pp.377-394, 1996. http://dx.doi.org/10.1002/ (SICI) 1520-6688(199622) 15:3<377::AID-PAM3>3.0.CO;2-F

[35] N. Casalino, S. Armenia, D. Canini, "A system dynamics approach to the paper dematerialization process in the Italian public administration", in The Interdisciplinary Aspects of Information Systems Studies, A. D’Atri, M. De Marco, N. Casalino. Eds., ItAIS, Physica-Verlag, Springer, Heidelberg, Germany, pp. 399408, 2008.

\section{AUTHORS}

F. Capriglione is Full Professor of Law and Economics and Dean of Law Faculty at Guglielmo Marconi University. Besides, he is Director of Master in Regulation of the Activities and the Financial Markets at LUISS Guido Carli University. His research interest areas are European banking law, institutional assets of financial top management, regulation of banking and financial markets, banking supervision and operations of financial intermediaries. $\mathrm{He}$ is author of over 300 peer-reviewed scientific publications and fifteen books (e-mail: f.capriglione@unimarconi.it).

N. Casalino is Associate Professor of Business Organization and Human Resource Management as well as Director of Master in Business Administration and Master in Human Resources and Organization at Guglielmo Marconi University - Department of Business Strategy and Innovation. He obtained a Ph.D. in Business Information Systems Management at LUISS Guido Carli University and he is Director of Centre for Studies and Research on the Economy of the Networks and New Professionals (CERP), Rome, Italy. His research interest areas are in business organization and human resource management, corporate learning, enterprise resource planning, CSCW, groupware and decision systems. He is author of over 80 peer-reviewed scientific publications and four books (email:n.casalino@unimarconi.it).

Manuscript received 30 June 2014. Published as submitted by the authors 08 December 2014.. Although the article is the result of joint observations of the two authors, the abstract and the paragraphs $2,3,4,5$ have to be attributed to Francesco Capriglione, while the paragraphs 1, 6, 7, 8, 9, 10, 11, 12 to Nunzio Casalino. 